\title{
Real Time Ultrasound Elastography in Musculoskeletal Manifestations of Mucopolysaccharidosis
}

\author{
Rosendo Ullot Font ${ }^{1}$, Pilar Rovira Martí1 , Emilio J Inarejos Clemente ${ }^{2}$, Mar 0’Callaghan Gordo ${ }^{3}$, Ramón Huguet \\ Carol $^{1}$ and Mercè Pineda Marfa $^{3}$
}

${ }^{1}$ Department of Pediatric Orthopedics, Sant Joan de Déu Hospital, Spain

${ }^{2}$ Department of Radiology, Sant Joan de Déu Hospital, Spain

${ }^{3}$ Department of Neurology, Sant Joan de Déu Hospital, Spain

Submission: November 08, 2019; Published: November 26, 2019

*Corresponding author: Pilar Rovira Martí, Department of Pediatric Orthopedics, Sant Joan de Déu Hospital, Passeig de Sant Joan de Déu, 2. Esplugues de Llobregat. 08950, Barcelona, Spain

\begin{abstract}
Background: Mucopolysaccharidosis (MPSs) are a group of metabolic disorders caused by several different enzyme deficiencies that cause multi-systemic affection

Aim: The aim of this study was to assess the capability of ultrasound elastography (SE) in evaluating the tendons stiffness in patients with diagnosis of MPSs correlating with clinical and physical examination.

Method: We evaluated 15 patients affected of MPS during a year and a half (6 men and 9 women, median age of 10 years, range 3-39). General data such as the type of mucopolysaccharidosis, the enzymatic deficiency, storage product, genetic defect, treatments and general symptoms were recorded. Exhaustive orthopedic examination has been performed and orthopedic surgeries have been recorded. The functional exercise capacities were evaluated with the Six-Minute Walk Test. For Sanfilippo disease we used a disability scale that measures ambulation, behavior, speech, swallowing, and epilepsy with a score in each category. One paediatric radiologist with specific training in musculoskeletal disorders performed the ultrasound elastography examinations in all subjects.
\end{abstract}

Results: We have found echographic alterations in different locations of patients with mucopolysaccharidosis that correspond to what is found in the elastography.

Conclusion: The results of this work are promising as to the usefulness of elastography in the assessment of tissue stiffness in deposit diseases such as MPSs. Their greater sensitivity to detect deposits may be useful for us to evaluate the enzymatic treatments, the BMT or the surgical treatments that we perform to these patients. Level III of evidence

Keywords: Elastography; Mucopolysaccharidosis; Tendon stiffness; Ultrasound; Orthopedics

Abbreviations: Mucopolysaccharidosis (MPSs); Glycosaminoglycans (GAGs); 6-min walk test (6MWT); Replacement enzymatic treatment (ERT); Bone marrow transplant (BMT)

\section{Introduction}

Mucopolysaccharidosis (MPSs) are a group of inborn metabolic disorders caused by several different enzyme deficiencies that lead to progressive lysosomal storage of glycosaminoglycans (GAGs). MPS is a group of disorders with multi-systemic affection (nervous, skeletal, respiratory, cardiovascular, gastrointestinal, ocular, dental and auditory systems). They present slow clinical progression of the symptoms that may cause severe morbidity and early mortality depending on the molecular genetic mutation. A delay in the final diagnosis in some of these patients frequently occur, especially in those with more attenuated forms of disease.

MPSs were described in 1917 when Charles Hunter reported that two young male siblings presented similar characteristics, a large abdomen, and bone dysplasia. In 1919, Dr. Gertrud Hurler described the visceromegaly and bone abnormalities present in two unrelated boys with similar features [1].In 1929, Luis Morquio described a form of "familial skeletal dystrophy" affecting four out of five children born to consanguineous parents [2]. In 1962, an attenuated form of hurler syndrome was described by Scheie et al. [3] and another form of mental retardation associated with mucopolysacchariduria, but with less pronounced visceral and skeletal manifestations, was identified by Sanfilippo et al. [4]. In 1963, Maroteaux et al. described a new form of dysostosis with 
mucopolysacchariduria, but without cognitive impairment [5]. In 1973, Sly syndrome was described and the most recent MPSs was described by Natowicz et al. in 1996 [6,7].

The seven major types of MPS are categorized based on the specific enzyme deficiency present, the major clinic manifestations or both [8]. All are progressive and autosomal recessive inheritance diseases, except MPS type II that is

Table 1: Types of MPS.

\begin{tabular}{|c|c|c|c|c|}
\hline Number & Eponym & Gen & Enzyme deficiency & Storage product \\
\hline $\mathbf{I}$ & Hurler /Scheie & IDUA & alfa-L-iduronidase & Heparan sulfate / dermatan sulfate \\
\hline II & Hunter & IDS & Iduronate 2-sulfatase & Heparan sulfate / dermatan sulfate \\
\hline IIIA & Sanfilippo A & SGSH & Heparan-N-sulfatase & \multirow{4}{*}{ Heparan sulfate } \\
\hline IIIB & Sanfilippo B & NAGLU & a-N-acetylglucosaminidase & \\
\hline IIIC & Sanfilippo C & HGSNAT & a-glucosaminide acetyltransferase & \\
\hline IIID & Sanfilippo D & GNS & $\mathrm{N}$-acetilglucosamina 6 sulfatasa & \\
\hline IV A & Morquio A & GALNS & $\mathrm{N}$-acetilgalactosamina 6 sulfatasa & Keratan sulfate / chondroitin sulfate \\
\hline IV B & Morquio B & GLBI & beta-galactosidase & Keratan sulfate \\
\hline VI & Morateaux-Lamy & ARSB & $\mathrm{N}$-acetylgalactosamine 4-sulfatasae & Dermatan sulfate \\
\hline VII & Sly & GUSB & Beta-glucoronidase & $\begin{array}{l}\text { Heparan sulfate / dermatan sulfate / chondroitin } \\
\text { sulfate }\end{array}$ \\
\hline IX & Natowicz & HYAL1 & Hyaluronidase & Hyaluronic acid \\
\hline
\end{tabular}

Ultrasonography is a useful imaging tool to characterize soft tissues, such as tendons, ligaments and synovial membranes [10] Recently, the ultrasound elastography has become commercially available for further assessment of tissues, in addition to the standard B-mode and Doppler imaging. The elastic properties of tissues are different from the acoustic impedance used to create B-mode imaging and the flow properties used within Doppler imaging, hence elastography provides a different form of tissue assessment and possibly showing pathology before it can be detected on B-mode imaging. This may be of particular use in the musculoskeletal system of the mucopolysaccharidosis patients [10].

The term elastography was described by Ophir et al. [11] as a method of portraying the strain properties of biological tissue. In medical usage, elastography requires the application of a mechanical stress to the tissues and then measurement of the displacement before and immediately after the stress as an estimate of the strain [12]. There are currently two main elastography methods in general clinical usage, namely compression/strain elastography and shear wave elastography.

\section{Strain Elastography (SE)}

In strain, or compression elastography, a force (i.e., stress) is applied from the transducer by repetitive manual pressure and the displacement (strain) is calculated from the return velocities of the tissues with respect to time. Motion intrinsic to the subject can also be used as the stress generator, such as aortic pulsation, however this is less useful in the musculoskeletal system where more superficial structures are of interest. sexually inherited (X chromosome). Clinical features and severity of symptoms vary widely both among and within the seven major types of MPS Table 1 . The accumulation of partially degraded GAGs in the lysosomes of connective tissue cells and chondrocytes is thought to be responsible for most of the musculoskeletal manifestation seen in the different types of MPS [9].
Measuring the displacement (strain) of the tissues secondary to an applied force (stress) gives a qualitative map of the elastic modulus distribution, termed an elastogram. This elastogram is colour coded and often superimposed on a greyscale B mode image for anatomical localization. True quantitative measures cannot be taken from this elastogram, as the applied force is unknown. A semiquantitative evaluation, however, can be determined from the ratio of the displacement of the tissue of interest and an adjacent structure, such as subcutaneous fat. Strain elastography has many potential disadvantages, including the variability in the pressure applied to the tissue. This can be partly compensated for by a graphical representation of the adequacy of the compression, however, the potential for interobserver and intraobserver variation remains [13].

\section{Shear Wave Elastography}

Shear wave elastography applies a vibration to tissues through a focused ultrasound pulse, generated by the transducer. This deposition of energy within the tissues creates transverse waves, or shear waves, which are perpendicular to the push pulse. The shear wave velocities can be measured from Doppler frequency modulation of simultaneously transmitted probing ultrasound waves. Young's modulus can then be estimated as a function of the shear wave velocity. The stiffer the tissue is (the less compliant to shear forces), the faster the propagated shear waves within it. Although shear wave elastography is likely to be more reproducible than strain elastography owing to the standardized applied stress, it still has limitations. Shear waves are attenuated at depth and thus very deep tissues $(>9 \mathrm{~cm}$ from the skin) cannot be assessed. Axial-strain sonoelastography 
and share-wave elastography are relatively new, non-invasive, real-time techniques that evaluate the mechanical properties of tissues.

\section{Materials and Methods}

This study evaluated 15 patients affected of MPS of our hospital database (4 Hurler-Scheie (26'6\%), 5 Sanfilippo $(33,3 \%)$ [2 type A, 2 Type B, 1 Type C], 3 Morquio A (20\%), 3 Maroteaux-Lamy (20\%)) during a year and a half (6 men and 9 women, median age of 10 years, range 3-39). The hospital ethics board committee approved the study. Voluntary informed consent was obtained from all patients included in protocol. The patients' characteristics were summarized with frequencies and percentages or as mean or median and range. General data such as the type of mucopolysaccharidosis, the enzymatic deficiency, storage product, genetic defect, treatments and general symptoms were recorded. Exhaustive orthopedic examination has been performed and orthopedic surgeries have been recorded.

Multiple values have been collected for orthopedic assessment, including height, body proportions, angular deviations, foot and hand alterations, deviations and affections in the vertebral column. Ambulation and joint stiffness or laxity have been assessed. The most frequent surgeries presented by patients with MPS have been collected. Recording the age and date of surgeries for carpal tunnel release, trigger finger release, hemiepiphysiodesis, hip and knee osteotomies and surgeries on the spine. The functional exercise capacities were evaluated with the Six-Minute Walk Test. For Sanfilippo disease we used a disability scale that measures ambulation, behavior, speech, swallowing, and epilepsy with a score in each category [14].

The 6-min walk test (6MWT) has gained importance in the assessment of functional exercise capacity in patients with chronic disease $[15,16]$. It has proved to be reliable, inexpensive, safe and easy to apply. In addition, it correlates well with important outcomes including death [17]. The 6MWTs were performed following ATS guidelines [18]. The evaluated parameters were six-minute walking distance in meters and changes in oxygen saturation and heart rate during exercise measured using a lightweight portable pulse oximeter. Pre-and post-6MWT dyspnoea were measured using the Borg scale [19].

One paediatric radiologist with specific training in musculoskeletal disorders performed the ultrasound elastography examinations in all subjects. The B-mode and elastographic images were shown simultaneously side by side on a split-screen display. Images in SE were performed by applying mild compression with the transducer. We used a scale (1-normal, 2-minimum deposit, 3-moderate deposit, 4-severe deposit) to be able to analyse the results in the 2 types of ultrasound. All patients included in the study undertook US of the lower limbs, evaluating the Achilles tendon, patellar tendon and anterior rectus and US of the upper limbs, evaluating the carpal tunnel and flexor tendons of all fingers. The statistical analysis was performed using the SPSS software package program (SPSS, Chicago, IL, USA) version 20. 0 ..

\section{Results}

Consanguinity was detected in $4(26,6 \%)$ patients of our study (1 Morquio, 2 Sanfilippo, 1 Hurler). From the clinical perspective we can distinguish three types of presentation according to the predominant affection: classical storage disease (MPS I, II, VI and VII), neurodegenerative disease (MPS I, II and III) and bone dysplasia (MPS IV). A short stature was detected in all patients except patients with Sanfilippo disease and in a patient with Hurler-Scheie disease, 3 years-old, who was in enzymatic treatment for more than 1 year. As regards the otorhinolaryngology alterations (otitis, deafness, adenoid and amygdalin hypertrophy), were found in all patients with HurlerScheie and Maroteaux-Lamy disease, two of five Sanfilippo and one of three Morquio. Corneal opacities were found in two of four Hurler/Scheie, two of three Morquio and two of three Maroteaux-Lamy. Cardiac valvopathy only was detected in one Morquio, one Maroteaux-Lamy and two Hurler-Scheie and hepatoesplenomegaly only was found in a Hurler-Scheie and in a Morquio disease. Neurological impairment was detected in all Sanfilippo patients.

Bone marrow transplant (BMT) only was performed in two patients with MPS I (patient no 4 and no 6), patient number 6 had received replacement enzymatic treatment (ERT) with laronidase (Aldurazyme ${ }^{\circledR}$ ) before the transplant. Patient 3 and 14 with MPS I had received the same ERT. All the patients with MPS VI ( $\mathrm{n} \div$ 5, no 11, no 12) were receiving ERT with galsulfase (Naglazyme $($ )). Patient $n \circ 1$ and $n \div 2$, with MPS IVA were treated with elosulfase alfa (Vimizim ${ }^{\circledR}$ ) and patient $n$ o 13 with the same diagnosis were pending to start the ERT. The patients with Sanfilippo disease didn't have a replacement enzymatic treatment or bone marrow transplant.

An orthopedic assessment was made up of several items (short neck, short trunk, kyphoscoliosis, subluxation C1-C2, cervical myelopathy, cervical stenosis, platyspondylea, pectus carinatum, genu valgus, genu varum, coxa valga, acetabular dysplasia, femoral dysplasia, hip dislocation, flatfoot, clubfoot, clinical Madelung and ambulation). The patients with more orthopedic involvement were Morquio type and the least affected were Sanfilippo disease. In the 5 patients Sanfilippo we only found one flatfoot and one patient with coxa valga, four of five of these patients use wheelchair-bound and the average age of them was 33 years. Clumsiness were present in all Hurler-Scheie patients. In Morquio disease, one patient walked awkwardly, another had an assisted walk outside and the other was in a wheelchair. In the three patients with Maroteaux-Lamy, one patient walks awkwardly, another had an assisted walk outside and third was in a wheelchair for a cervical myelopathy. Patients with MPS IVA had joint laxity, hip dislocation and Madelung deformity didn't found in the other types of MPS. Cervical myelopathy and C1- 


\section{Orthopedics and Rheumatology Open Access Journal (OROAJ)}

C2 subluxation were found in MPS IV and VI. Pectus carinatum was detected in MPS I and MPS IV. Genu valgus, short neck, short

Table 2: Sanfilippo disability scale. trunk, kyphoscoliosis, platyspondylea and acetabular dysplasia were diagnosed in all types of MPS analysed less Sanfilippo type.

\begin{tabular}{|c|c|c|c|c|c|}
\hline Sanfilippo disability scale & № 7 & № 8 & № 9 & № 10 & №15 \\
\hline \multicolumn{6}{|l|}{ Ambulation } \\
\hline $\begin{array}{c}\text { Clumsiness } 1 \\
\text { Autonomous gait apraxia } 2 \\
\text { Outdoor assisted ambulation } 3 \\
\text { Indoor assisted ambulation } 4 \\
\text { Wheelchair bound } 5\end{array}$ & 5 & 5 & 5 & 5 & 1 \\
\hline \multicolumn{6}{|l|}{ Behavior } \\
\hline $\begin{array}{c}\text { Occasional hyperactivity/irritability } 1 \\
\text { Daily crying and screaming } 2 \\
\text { Nocturnal awakening, irritability and crying } 3 \\
\text { Aggression controlled with sedative treatment } 4\end{array}$ & 3 & 1 & 4 & 3 & 1 \\
\hline \multicolumn{6}{|l|}{ Language } \\
\hline $\begin{array}{c}\text { Delay speech } 1 \\
\text { Dyslalic or dysarthric speech but understandable } 2 \\
\text { Language only understood by the family } 3 \\
\text { Nonverbal communication only } 4 \\
\text { Total absence of communication } 5\end{array}$ & 4 & 5 & 5 & 5 & 3 \\
\hline \multicolumn{6}{|l|}{ Swallowing } \\
\hline $\begin{array}{c}\text { Chewing difficulty } 1 \\
\text { Occasional dysphagia } 2 \\
\text { Daily dysphagia } 3 \\
\text { Nasogastric tube/ button feeding } 4\end{array}$ & 3 & 2 & 3 & 4 & 1 \\
\hline \multicolumn{6}{|l|}{ Epilepsy } \\
\hline $\begin{array}{l}\text { Seizures without treatment } 1 \\
\text { Epilepsy controlled with anticonvulsants } 2 \\
\text { Epilepsy not controlled with anticonvulsants } 3\end{array}$ & 2 & 0 & 2 & 3 & 0 \\
\hline \multicolumn{6}{|l|}{ TOTAL } \\
\hline & 17 & 13 & 19 & 20 & 6 \\
\hline Light (1-6) moderate (7-14) severe (15-21) & Severe & Moderate & Severe & Severe & Light \\
\hline
\end{tabular}

For Sanfilippo disease we used the Sanfilippo disability scale described by Delgadillo et al. [14] detailed in Table 2. There were three patients with severe disability, one moderate and one light. We present de results of the 6MWT and use the graphics of Geiger et al. [20] to compare it with normal population of same age and gender (Table 3 ). In the rest of the patients the test could not be performed because they could not walk. The surgeries

Table 3: 6-minute walking test results.

\begin{tabular}{|c|c|c|c|c|c|c|c|}
\hline Results 6MWT & oㅜ & No 4 & № 5 & № 6 & № 11 & №13 & №14 \\
\hline Age & 10 & 5 & 10 & 8 & 15 & 4 & 7 \\
\hline Gender & M & F & F & M & F & F & M \\
\hline Reference 95\% CI & $656.5-689.2$ & $464.7-539.1$ & $647.4-676.3$ & $564.0-591.6$ & $651.0-675.0$ & $464.7-539.1$ & $564.0-591.6$ \\
\hline Patient meters & 168 & 447 & 159 & 480 & 411 & 240 & 530 \\
\hline \% of expected for age and gender & $25 \%$ & $90 \%$ & $24 \%$ & $82 \%$ & $62 \%$ & $48 \%$ & $90 \%$ \\
\hline
\end{tabular}

The results of ultrasonography have been represented in the following (tables 4-7), dividing patients by type of MPS and whether they have received treatment. Patient number 7 is a patient with MPS type IIIB of 35 years with a very severe musculoskeletal affection in which it was not possible to perform performed in the patients were carpal tunnel release and trigger finger release in all patients with MPS I and in almost every MPS VI, knee hemiepiphysiodesis in 2/3 MPS IV and 1/3 MPS VI, a hip osteotomy in a patient with Morquio disease and in other patient with the same disease a knee osteotomy. All the patients with Maroteaux-Lamy required a cervical decompression and a patient with Morquio required an occipitocervical fusion. 


\section{Orthopedics and Rheumatology Open Access Journal (OROAJ)}

an ultrasound was performed initially with ERT and after the the different degree of involvement of the anterior rectus in the BMT. In figure 2 we present the improvement in deposits in same patient both b-mode and elastography after treatment. Figure 3 shows

Table 4: Hurler and Hurler-Scheie ecographic results.

\begin{tabular}{|c|c|c|c|c|c|c|c|c|c|c|}
\hline \multicolumn{11}{|c|}{ Hurler / Hurler-Scheie (I) } \\
\hline & \multicolumn{6}{|c|}{ ERT } & \multicolumn{4}{|c|}{ BMT } \\
\hline & \multicolumn{2}{|c|}{$n^{\circ} 3$} & \multicolumn{2}{|c|}{$n^{o} 6$} & \multicolumn{2}{|c|}{$n^{\circ} 14$} & \multicolumn{2}{|c|}{$n^{0} 6$} & \multicolumn{2}{|c|}{$n^{\circ} 4$} \\
\hline & B-Mode & Elasto & B-Mode & Elasto & B-Mode & Elasto & B-Mode & Elasto & B-Mode & Elasto \\
\hline & \multicolumn{10}{|c|}{ Achilles } \\
\hline $\mathrm{R}$ & 1 & 2 & 1 & 1 & 1 & 1 & 1 & 1 & 1 & 1 \\
\hline \multirow[t]{2}{*}{$\mathrm{L}$} & 1 & 1 & 1 & 1 & 1 & 1 & 1 & 1 & 1 & 1 \\
\hline & \multicolumn{10}{|c|}{ Patellar tendon } \\
\hline $\mathrm{R}$ & 1 & 2 & 1 & 1 & 2 & 2 & 1 & 1 & 2 & 3 \\
\hline \multirow[t]{2}{*}{$\mathrm{L}$} & 1 & 2 & 1 & 1 & 2 & 2 & 1 & 1 & 2 & 4 \\
\hline & \multicolumn{10}{|c|}{ Anterior Rectus } \\
\hline $\mathrm{R}$ & 1 & 2 & 4 & 4 & 3 & 3 & 2 & 1 & 1 & 2 \\
\hline \multirow[t]{2}{*}{$\mathrm{L}$} & 1 & 1 & 4 & 4 & 3 & 3 & 1 & 1 & 1 & 2 \\
\hline & \multicolumn{10}{|c|}{ Carpal Tunnel } \\
\hline $\mathrm{R}$ & 1 & 1 & 1 & 1 & 4 & 4 & 1 & 1 & 1 & 1 \\
\hline \multirow[t]{2}{*}{$\mathrm{L}$} & 1 & 1 & 1 & 1 & 4 & 4 & 1 & 1 & 1 & 1 \\
\hline & \multicolumn{10}{|c|}{ Flexor tendon } \\
\hline $1 \stackrel{\circ}{R}$ & 1 & 1 & 1 & 1 & 3 & 3 & 1 & 1 & 1 & 1 \\
\hline $1^{\circ} \mathrm{L}$ & 1 & 1 & 1 & 1 & 3 & 3 & 1 & 1 & 1 & 1 \\
\hline $2^{\circ} \mathrm{R}$ & 1 & 1 & 1 & 1 & 3 & 3 & 1 & 1 & 1 & 1 \\
\hline $2^{\circ} \mathrm{L}$ & 1 & 1 & 1 & 1 & 3 & 3 & 1 & 1 & 1 & 1 \\
\hline 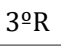 & 1 & 3 & 1 & 1 & 3 & 3 & 1 & 1 & 1 & 1 \\
\hline $3 \stackrel{\circ}{L}$ & 1 & 1 & 1 & 1 & 3 & 3 & 1 & 1 & 1 & 1 \\
\hline $4 \stackrel{\circ}{R}$ & 1 & 1 & 1 & 1 & 3 & 3 & 1 & 1 & 1 & 1 \\
\hline $4^{\circ} \mathrm{L}$ & 1 & 1 & 1 & 1 & 3 & 3 & 1 & 1 & 1 & 1 \\
\hline $5 \% \mathrm{R}$ & 1 & 1 & 1 & 1 & 3 & 3 & 1 & 1 & 1 & 1 \\
\hline 5느 & 1 & 1 & 1 & 1 & 3 & 3 & 1 & 1 & 1 & 1 \\
\hline
\end{tabular}

R Right; L left; Elasto Elastography;; $1^{\circ}, 2^{\circ}, 3^{\circ}, 4^{\circ}, 5^{\circ}$ finger.

Table 5: Morquio ecographic results.

\begin{tabular}{|c|c|c|c|c|c|c|}
\hline \multicolumn{7}{|c|}{ Morquio (IV) } \\
\hline & \multicolumn{4}{|c|}{ ERT } & \multirow{2}{*}{\multicolumn{2}{|c|}{$\begin{array}{c}\text { No treatment } \\
n^{\circ} 13\end{array}$}} \\
\hline & \multicolumn{2}{|c|}{$n^{o} 1$} & \multicolumn{2}{|c|}{$n^{\circ} 2$} & & \\
\hline & B-Mode & Elasto & B-Mode & Elasto & B-Mode & Elasto \\
\hline & \multicolumn{6}{|c|}{ Achilles } \\
\hline $\mathrm{R}$ & 1 & 3 & 1 & 1 & 1 & 3 \\
\hline \multirow[t]{2}{*}{$\mathrm{L}$} & 3 & 3 & 1 & 1 & 1 & 1 \\
\hline & \multicolumn{6}{|c|}{ Patellar tendon } \\
\hline $\mathrm{R}$ & 1 & 1 & 1 & 1 & 1 & 1 \\
\hline \multirow[t]{2}{*}{$\mathrm{L}$} & 1 & 1 & 1 & 1 & 1 & 1 \\
\hline & \multicolumn{6}{|c|}{ Anterior Rectus } \\
\hline $\mathrm{R}$ & 1 & 1 & 2 & 2 & 1 & 1 \\
\hline \multirow[t]{2}{*}{$\mathrm{L}$} & 2 & 2 & 2 & 2 & 1 & 1 \\
\hline & \multicolumn{6}{|c|}{ Carpal Tunnel } \\
\hline
\end{tabular}




\section{Orthopedics and Rheumatology Open Access Journal (OROAJ)}

\begin{tabular}{|c|c|c|c|c|c|c|}
\hline $\mathrm{R}$ & 1 & 1 & 1 & 1 & 1 & 1 \\
\hline $\mathrm{L}$ & 1 & 1 & 1 & 1 & 1 & 1 \\
\hline & \multicolumn{6}{|c|}{ Flexor tendon } \\
\hline $1 \stackrel{\circ}{\circ}$ & 1 & 1 & 1 & 1 & 1 & 1 \\
\hline $1^{\circ} \mathrm{L}$ & 1 & 1 & 1 & 1 & 1 & 1 \\
\hline $2^{\circ} \stackrel{\circ}{ }$ & 1 & 1 & 1 & 1 & 1 & 1 \\
\hline $2^{\circ} \mathrm{L}$ & 1 & 1 & 1 & 1 & 1 & 1 \\
\hline $30 R$ & 1 & 1 & 1 & 1 & 1 & 1 \\
\hline $3^{\circ} \stackrel{\mathrm{L}}{ }$ & 1 & 1 & 1 & 1 & 1 & 1 \\
\hline $4 \stackrel{0}{2}$ & 1 & 1 & 1 & 1 & 1 & 1 \\
\hline $4^{\circ} \mathrm{o} \mathrm{L}$ & 1 & 1 & 1 & 1 & 1 & 1 \\
\hline $5 \div \mathrm{R}$ & 1 & 1 & 1 & 1 & 1 & 1 \\
\hline $5^{\circ} \mathrm{L}$ & 1 & 1 & 1 & 1 & 1 & 1 \\
\hline
\end{tabular}

R Right; L left; Elasto Elastography; $1^{\circ}, 2^{\circ}, 3^{\circ}, 4^{\circ}, 5^{\circ}$ finger.

Table 6: Maroteaux-Lamy ecographic results.

\begin{tabular}{|c|c|c|c|c|c|c|}
\hline \multicolumn{7}{|c|}{ Maroteaux-Lamy (VI) } \\
\hline & \multicolumn{6}{|c|}{ ERT } \\
\hline & \multicolumn{2}{|c|}{$n^{\circ} 5$} & \multicolumn{2}{|c|}{$n-11$} & \multicolumn{2}{|c|}{$n^{\circ} 12$} \\
\hline & B-Mode & Elasto & B-Mode & Elasto & B-Mode & Elasto \\
\hline & \multicolumn{6}{|c|}{ Achilles } \\
\hline $\mathrm{R}$ & 1 & 1 & 4 & 4 & 4 & 4 \\
\hline \multirow[t]{2}{*}{$\mathrm{L}$} & 1 & 1 & 3 & 3 & 4 & 4 \\
\hline & \multicolumn{6}{|c|}{ Patellar tendon } \\
\hline $\mathrm{R}$ & 1 & 1 & 2 & 2 & 3 & 3 \\
\hline \multirow[t]{2}{*}{$\mathrm{L}$} & 1 & 1 & 1 & 1 & 3 & 3 \\
\hline & \multicolumn{6}{|c|}{ Anterior Rectus } \\
\hline $\mathrm{R}$ & 1 & 1 & 1 & 2 & 1 & 2 \\
\hline \multirow[t]{2}{*}{$\mathrm{L}$} & 1 & 1 & 2 & 2 & 1 & 3 \\
\hline & \multicolumn{6}{|c|}{ Carpal Tunnel } \\
\hline $\mathrm{R}$ & 3 & 3 & 3 & 3 & 2 & \\
\hline \multirow[t]{2}{*}{$\mathrm{L}$} & 3 & 3 & 2 & 3 & 2 & 3 \\
\hline & \multicolumn{6}{|c|}{ Flexor tendon } \\
\hline $190 \mathrm{R}$ & 2 & 1 & 1 & 1 & 2 & \\
\hline 1으 & 2 & 1 & 1 & 1 & 1 & 1 \\
\hline $2 \stackrel{\circ}{R}$ & 2 & 1 & 1 & 1 & 2 & \\
\hline $2^{\circ} \mathrm{L}$ & 2 & 1 & 1 & 1 & 1 & 1 \\
\hline $3 \% \mathrm{R}$ & 2 & 1 & 1 & 1 & 2 & \\
\hline $3 \div \mathrm{L}$ & 2 & 1 & 1 & 1 & 1 & 1 \\
\hline $4 \div \mathrm{o} R$ & 2 & 1 & 1 & 1 & 2 & \\
\hline $4 \stackrel{\circ}{\mathrm{L}}$ & 2 & 1 & 1 & 1 & 1 & 1 \\
\hline 50R & 2 & 1 & 1 & 1 & 2 & \\
\hline 5느 & 2 & 1 & 1 & 1 & 1 & 1 \\
\hline
\end{tabular}

R Right; L left; Elasto Elastography; $1^{\circ}, 2^{\circ}, 3^{\circ}, 4^{\circ}, 5^{\circ}$ finger

Table 7: Maroteaux-Lamy ecographic results.

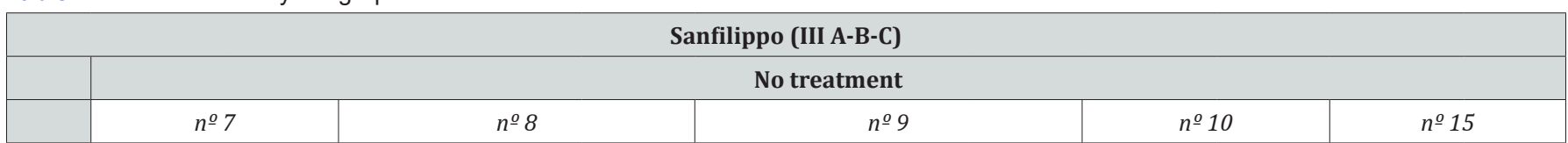




\section{Orthopedics and Rheumatology Open Access Journal (OROAJ)}

\begin{tabular}{|c|c|c|c|c|c|c|c|c|c|c|}
\hline & B-Mode & Elasto & B-Mode & Elasto & B-Mode & Elasto & B-Mode & Elasto & B-Mode & Elasto \\
\hline & \multicolumn{10}{|c|}{ Achilles } \\
\hline $\mathbf{R}$ & & & 2 & 2 & 1 & 3 & 2 & 2 & 1 & 1 \\
\hline \multirow[t]{2}{*}{$\mathbf{L}$} & & & 2 & 2 & 1 & 3 & 2 & 2 & 1 & 1 \\
\hline & \multicolumn{10}{|c|}{ Patellar tendon } \\
\hline $\mathbf{R}$ & 1 & 1 & 3 & 3 & 1 & 3 & 1 & 1 & 1 & 2 \\
\hline \multirow[t]{2}{*}{$\mathbf{L}$} & 1 & 2 & 3 & 3 & 1 & 3 & 1 & 1 & 1 & 3 \\
\hline & \multicolumn{10}{|c|}{ Anterior Rectus } \\
\hline $\mathbf{R}$ & 1 & 1 & 4 & 4 & 1 & 2 & 3 & 3 & 1 & 2 \\
\hline \multirow[t]{2}{*}{$\mathbf{L}$} & 3 & 3 & 4 & 4 & 1 & 1 & 3 & 3 & 1 & 3 \\
\hline & \multicolumn{10}{|c|}{ Carpal Tunnel } \\
\hline $\mathbf{R}$ & & & 2 & 2 & 1 & 2 & 1 & 1 & 1 & 1 \\
\hline \multirow[t]{2}{*}{$\mathbf{L}$} & & & 2 & 2 & 1 & 1 & 1 & 2 & 1 & 1 \\
\hline & \multicolumn{10}{|c|}{ Flexor tendon } \\
\hline $1 \% \mathrm{R}$ & & & 1 & 1 & 1 & 1 & 1 & 1 & 1 & 1 \\
\hline $1 \mathbf{O}^{\mathrm{O}} \mathrm{L}$ & & & 1 & 1 & 1 & 1 & 1 & 1 & 1 & 1 \\
\hline $2^{\circ} \mathrm{R}$ & & & 1 & 1 & 1 & 1 & 1 & 1 & 1 & 1 \\
\hline $2^{\circ} \mathbf{L}$ & & & 2 & 2 & 1 & 1 & 1 & 1 & 1 & 1 \\
\hline $3 \% \mathrm{R}$ & & & 1 & 1 & 1 & 1 & 1 & 1 & 1 & 1 \\
\hline $3^{\circ}-\mathrm{L}$ & & & 2 & 2 & 1 & 1 & 1 & 1 & 1 & 1 \\
\hline $4^{\circ} \mathrm{R}$ & & & 1 & 1 & 1 & 1 & 1 & 1 & 1 & 1 \\
\hline $4^{\circ}=\mathrm{L}$ & & & 2 & 2 & 1 & 1 & 1 & 1 & 1 & 1 \\
\hline 5\%R & & & 1 & 1 & 1 & 1 & 1 & 1 & 1 & 1 \\
\hline $5^{\circ} \mathbf{-} \mathbf{L}$ & & & 2 & 2 & 1 & 1 & 1 & 1 & 1 & 1 \\
\hline
\end{tabular}

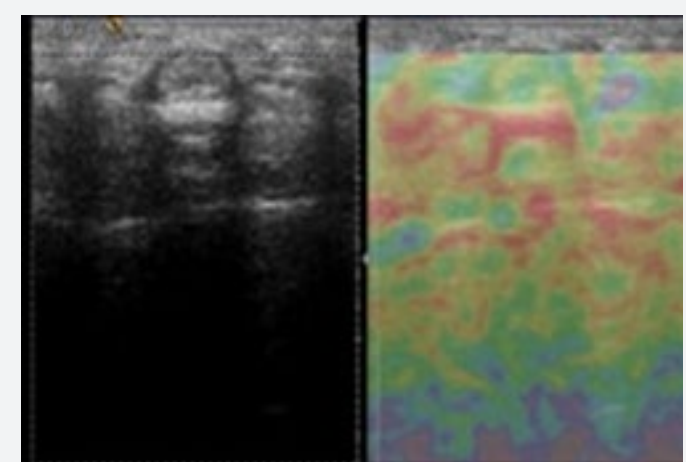

Figure 1a: Moderate involvement of the deep flexor tendon.

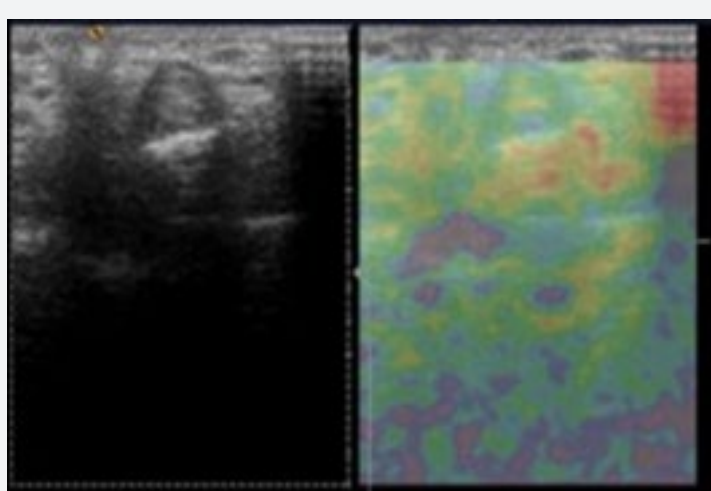

Figure 1b: No involvement in elastography.

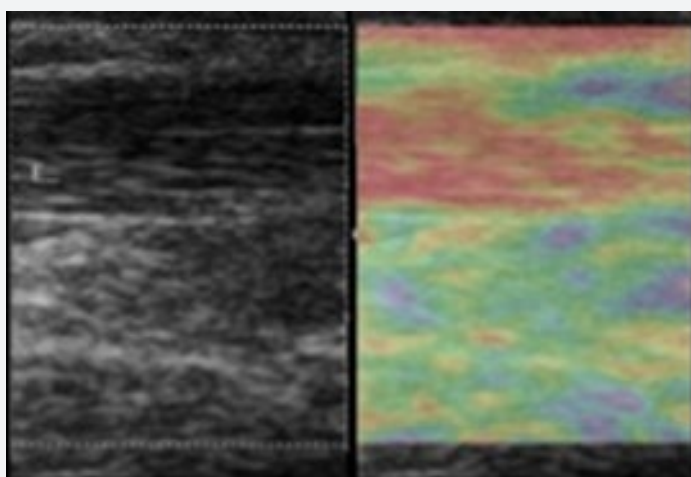

Figure 2a: Anterior rectus afectation.

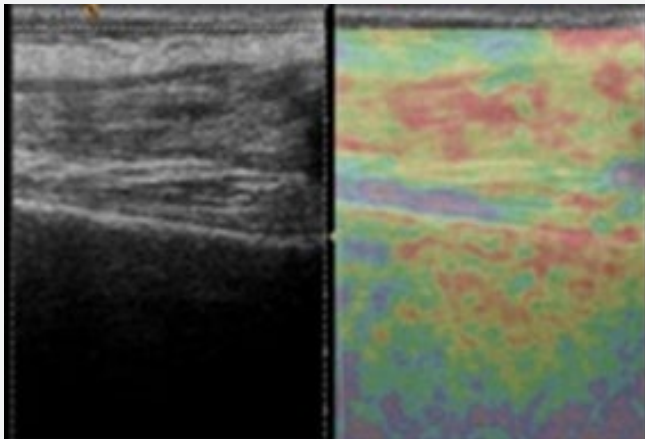

Figure 2b: Improvement after bone marrow transplant. 


\section{Orthopedics and Rheumatology Open Access Journal (OROAJ)}
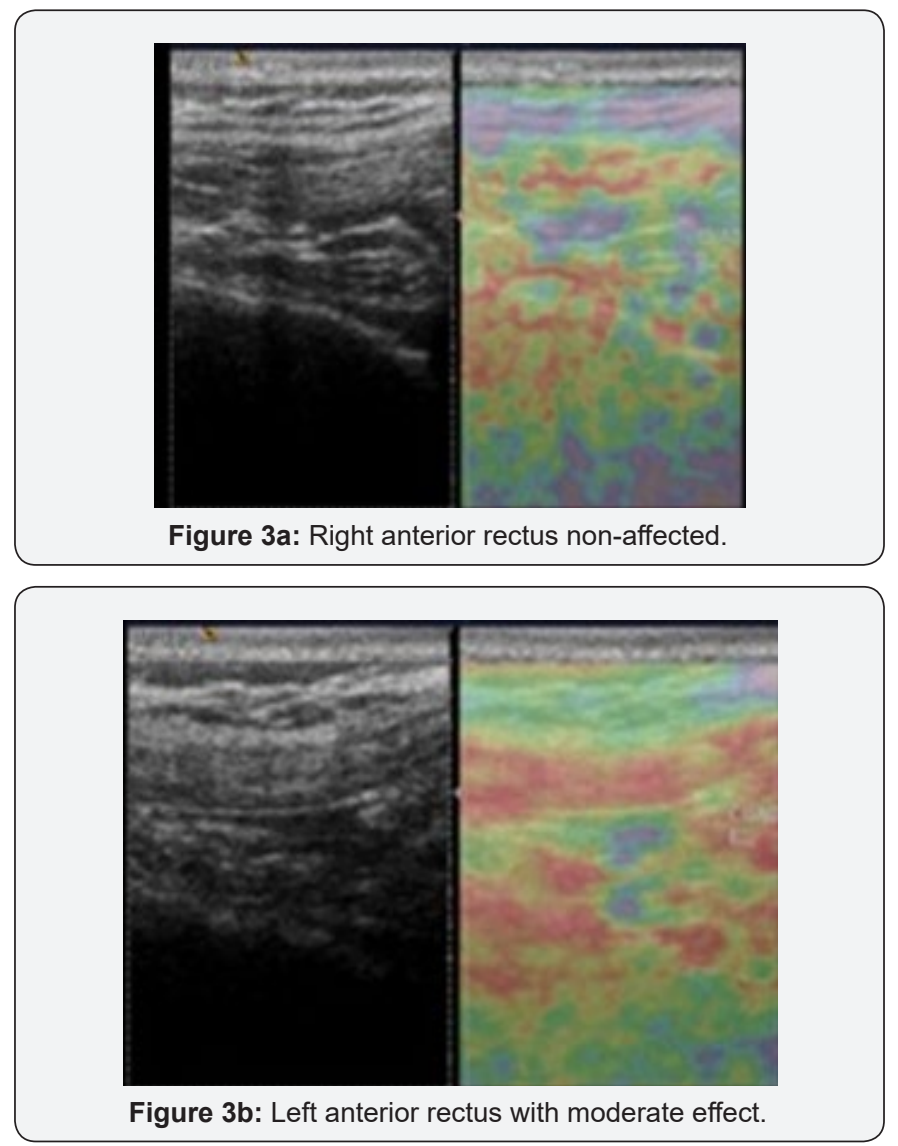

Discussion

We found short stature in all patients with Morquio and Maroteaux-Lamy disease, and all but one patient with HurlerScheie disease of 3 years with ERT since 2 years-old. Short stature, may be due to a disruption in the programmed maturation of the chondrocyte at the level of the growth plate [21], is a common feature in all types of MPS, except in Sanfilippo disease where we did not find any short stature, although it may be mild or under-recognized in the attenuated forms. Axial growth is usually more affected than appendicular growth resulting in disproportionately short stature [22].

Joint stiffness and contractures can be found in all types of MPS, except for MPS IV (Morquio syndrome), in which there is laxity, and MPS IX [22]. We found laxity in all patients with Morquio. These abnormalities are felt to arise secondary to infiltration by GAGs of the ligaments, tendons, joint capsules and other soft tissues in combination with epiphyseal and metaphyseal deformities owing to defective skeletal remodeling [9]. Stiffness and contractures preferentially affect the phalangeal joints; however, all joints can be affected, especially in the more severe forms. When the interphalangeal joints of the hands are affected, the characteristic claw hand deformity develops; often resulting in impaired hand function. The hypermobility results from metaphyseal deformities, hypoplasia of bones and degradation of connective tissues around the joint.
The most frequent musculoskeletal procedures were carpal tunnel and flexor release that is performed very early age 5.9 years (3.2-9.5 years), hemiepiphysiodesis, osteotomies, and spinal cord decompression surgeries. Carpal tunnel syndrome is uncommon in childhood. The median nerve compression occurs as a result of thickening of the flexor retinaculum and the tissues around the tendon sheaths [23]. All patients with MPS I and MPS VI were operated on for carpal tunnel release and all but one for flexor release. Trigger fingers in association with carpal tunnel syndrome are well recognized in patients with MPS [9]. Trigger occurs as a result of GAGs deposits in the capsular tissues of joints or flexor tendons [24]. The diagnosis of a trigger digit is usually made clinically; however, there may be role for high-resolution ultrasonography in determining the underlying cause for triggering [25]. The patient $\mathrm{n}-14$ with MPS I, was the most affected echographically and was pending a second release intervention.

Patients with MPS have an increased incidence of hypoplasia of the odontoid process that predisposes them to atlantoaxial instability. Spinal cord compression may occur as a result of atlanto-axial subluxation and lead to neurological complications, most commonly spastic tetra paresis; however, paraparesis and hemiparesis have also been reported [26]. Patients with Hurler syndrome (MPS I) and Morquio syndrome (MPS IV) appear to have the highest risk of developing odontoid hypoplasia, although it can occur in other types as well [27]. The combination of joint hypermobility of MPS IV and odontoid hypoplasia in these patients is the possible responsible for very high incidence of atlanto-axial subluxation. We found a cervical stenosis in a half of the patients of Hurler and subluxation C1C2 and cervical myelopathy in Morquio and Maroteaux-Lamy. All MPS VI needed cervical decompression and one MPS IV needed an occipitocervical fusion.

We have found echographic alterations in different locations of patients with mucopolysaccharidosis that correspond to what is found in the elastography. One of the most affected was anterior rectus tendon. In MPS I, we found a patient with severe deposits on B-Mode and elastography that improve to normal/ minimum deposit after the bone marrow transplantation. Only one of four patients with MPS I had moderate/severe affectation of tendons (except Achilles tendon), this patient, however, had a $90 \%$ of the result in $6 \mathrm{MWT}$ for age and gender. In Morquio disease we found only minimum deposit in anterior rectus of 2/3 patients and moderate deposits in Achilles of 2/3 patients. Although the patient with Morquio were the least affected in b-mode and elastography, they had poor results in 6MWT (25\% and $48 \%$ of expected for age and gender) and were the patient with greater orthopedic involvement. In MaroteauxLamy disease we found quite affectation in echographic findings. Achilles tendon was affected moderate/sever in 3/4 patients. All patients had minimum or moderate deposits in carpal tunnel and $2 / 3$ in patellar tendon and anterior rectus tendon, the flexor 
tendons of the hand were less affected. Instead the patients with Maroteaux-Lamy disease with less echographic affectation had a bad result (24\% of expected for age and gender) in 6MWT. In Sanfilippo disease we found minimum or moderate deposits in Achilles tendon in $3 / 4$ patients and in patellar tendon $4 / 5$. The anterior rectus tendon was the most affected and carpal tunnel and flexor tendons of the hands the least. The patient most affected was no8 that had a moderate affectation in Sanfilippo disability scale.

The first effective therapy for these severe and progressive disease was reported in 1980, when BMT was performed on an MPS I patient [28]. The first specific therapy approved for MPS was intravenous ERT for MPS I, followed by MPS VI [29], MPS II, and, recently MPS IVA [1]. BMT can prevent cognitive decline, improve upper airway disease, reduce hepatosplenomegaly, and improve mobility in severe form of MPS I before the age of 2.5 years; however, the cornea is not cleared, cardiac valve disease persists and skeletal changes progress. BMT dos does not seem to be an option for patients with MPS III and MPS IV, and its efficacy is controversial for patients with MPS type II [1]. ERT has arisen as an effective approach to alleviate some of the symptoms of MPS I [30], MPS II [31], and MPS VI [32], and more recently, for MPS IVA [33]. Presently approved treatments are unable to appropriately address, such as the neurological and skeletal manifestations [1].

Currently, to confirm de efficacy of the enzyme replacement therapy for mucopolysaccharidosis, the 6-minute walk test (6MWT) is used. Faced with the need to find a biomarker that is objective and may evaluate the evolution of these diseases and the therapeutic responses we consider that the elastography in musculoskeletal could be a good method to follow-up response to different treatments that exist for these patients. Extensive research has demonstrated the effectiveness of the use of elastography in differentiating malignant from benign lesions of the breast, thyroid, prostate and lymph node [34-37].

\section{Conclusion}

In conclusion we found that the most affected tendon in elastography and B-mode was anterior rectus tendon. We found an improvement in elastography finding after a BMT in one patient in which we were able to perform the test before and after the transplant. Patient least affected in echography were patients with Morquio disease and they had joint laxity, they had poor results in 6MWT and were the patient with greater orthopedic involvement. We are aware that functional test like 6MWT encompasses more capabilities than just tendinous deposits, but we were hopeful that elastography can have a role, for their greater sensitivity, to detect deposits and may be useful for us to evaluate the enzymatic treatments, the BMT or the surgical treatments that we perform to these patients. The results of this work are promising as to the usefulness of elastography in the assessment of tissue stiffness in deposit diseases such as mucopolysaccharidosis. Also, its comparison in healthy population to be able to carry out its validation and to evaluate its usefulness in the follow-up of the disease. To be able to perform a work with scientific and statistical quality it is imperative to be able to quantify the values obtained by the elastography with an echograph with specific software for it.

\section{Acknowledgement}

Acknowledgements to Biomarin for their assistance in this study.

\section{Conflict of Interest}

On behalf of all authors, the corresponding author states that there is no conflict of interest.

All procedures performed in studies involving human participants were in accordance with the ethical standards of the institutional and/or national research committee and with the 1964 Helsinki declaration and its later amendments or comparable ethical standards. "Informed consent was obtained from all individual participants included in the study.

\section{Reference}

1. Giugliani R, Federhen A, Vanzella C, Pasqualim G, da Silva L, et al. (2016) Emerging drugs for the treatment of mucopolysaccharidoses. Expert Opin Emerg Drugs 21(1): 9-26.

2. Morquio L (1929) Sur une forme de dystrophie osseuse familiale. Archives de médecine des infants 32: 129-135.

3. Scheie HG, Hambrick GWJ, Barness LA (1962) A newly reognized forme of Hurler's disease (gargoylism). Am J Ophtalmol 53: 753-769.

4. Sanfilippo S, Podosin R, Langer LJ (1963) Mental retardation associated with acid mucopolysacchariduria (heparin sulfate type). J Pediatr 63: 837-838.

5. Maroteaux P, Leveque B, Marie J, Lamy M (1963) [a New Dysostosis with Urinary Elimination of Chondroitin Sulfate B]. Presse Med (Une nouvelle dysostose avec 'elimination urinaire de chondroitine-sulfate b.) 71: 1849-1852.

6. Sly WS, Quinton BA, McAlister WH, Rimoin DL (1973) Beta glucuronidase deficiency: report of clinical, radiologic, and biochemical features of a new mucopolysaccharidosis. J Pediatr 82(2): 249-257.

7. Natowicz MR, Short MP, Wang Y, Dickersin GR, Gebhardt MC, Rosenthal DI, et al. (1996) Clinical and biochemical manifestations of hyaluronidase deficiency. N Engl J Med 335: 1029-1033.

8. Muenzer J (2004) The mucopolysaccharidosis: a heterogeneus group of disorders with variable pediatric presentations. J Pediatr 144: S27-S34.

9. Morishita K, Petty RE (2011) Musculoskeletal manifestations of mucopolysaccharidoses. Rheumatology (Oxford) 50 Suppl 5: v19-25.

10. Winn N, Lalam R, Cassar-Pullicino V (2016) Sonoelastography in the musculoskeletal system: Current role and future directions. World J Radiol 8(11): 868-879.

11. Ophir J, Alam S, Garra B, Kallel F, Konofagou E, Krouskop T, et al. (2001) Elastography: Imaging the elastic properties of soft tissues with ultrasound. J Med Ultrason 29(4): 155.

12. Taylor LS, Porter BC, Rubens DJ, Parker KJ (2000) Three-dimensional sonoelastography: principles and practices. Phys Med Biol 45: 14771494 . 
13. Drakonaki EE, Allen GM, Wilson DJ (2012) Ultrasound elastography for musculoskeletal applications. Br J Radiol 85(1019): 1435-1445.

14. Delgadillo V, O'Callaghan Mdel M, Artuch R, Montero R, Pineda M (2011) Genistein supplementation in patients affected by Sanfilippo disease. J Inherit Metab Dis 34(5): 1039-1044.

15. Enright PL (2003) The six-minute walk test. Respir Care 48(8): 783785.

16. Casanova C, Celli BR, Barria P, Casas A, Cote C, et al. (2011) Six Minute Walk Distance P (2011) The 6-min walk distance in healthy subjects: reference standards from seven countries. Eur Respir J 37: 150-156.

17. Cote CG, Casanova C, Marín JM, López MV, Pinto-Plata V, et al. (2008) Validation and comparison of reference equations for the six-minute walk test. Eur Respir J 31: 571-578.

18. ATS Committee on Proficiency Standards for Clinical Pulmonary Function Laboratories (2002) ATS statement: guidelines for the six-minute walk test. Am J Respir Crit Care Mad 166(1): 111-117.

19. Borg GA (1982) Psycho-physical bases of perceived exertion. Med Sci Sports Exerc 14(5): 377-381.

20. Geiger R, Strasak A, Tremi B, Gasser K, Kleinsasser A, Fischer V, et al. (2007) Six-minute walk test in children and adolescents. J Pediatr 150(4): 395-399.

21. Oussoren E, Brands MM, Ruijter GJ, der Ploeg AT, Reuser AJ (2011) Bone, joint and tooth development in mucopolysaccaridoses: relevance to therapeutic options. Biochim Biophys Acta 1812(11): 15421556.

22. Aldenhoven M, Sakkers RJ, Boelens J, de Koning TJ, Wulffraat NM (2009) Musculoskeletal manifestations of lysosomal storage disorders. Ann Rheum Dis 68(11): 1659-1665.

23. Al-Qattan MM, Thompson HG, Clarke HM (1996) Carpal tunnel syndrome in children and adolescents with no history of trauma. J Hand Surg Br 21(1): 108-111.

24. Van Heest AE, House J, Krivit W, Walker K (1998) Surgical tretament of carpal tunnel syndrome and trigger digits in children with mucopolysaccharide storage disorders. J Hand Surg Am 23(2): 236-243.

25. Kim HR, Lee SH (2010) Ultrasonographic assessment of clinically diagnosed trigger fingers. Rheumatol Int 30(11): 1455-1458.

26. Hachur E, Del Maestro R (2000) Mucopolysaccharidoses and spinal cord compression: case report and review of the literature with implications of bone marrow transplantation. Neurosurgery 47: 223-228.
27. Pastores GM (2008) Musculoskeletal complications encountered in the lysosomal storage disorders. Best Pract Res Clin Rheumatol 22(5): 937-947.

28. Hobbs JR (1981) Bone marrow transplantation for inborn errors. Lancet 2: 735-739.

29. Pineda M, O'Callaghan M, Fernandez Lopez A, Coll M, Ullot R, et al. (2016) Clinical evolution after enzyme replacement therapy in twins with the severe form of morateaux-Lamy syndrome. JIMD Rep 30: 7-14.

30. Wraith JE, Clarke LA, BecK M (2004) Enzyme replacement therapy for mucopolysaccharidosis I: a randomized, double-blined, placebo-controlled, multinational study of recombinant human alpha-L-iduronidase (laronidase). J Pediatr 144(5): 581-588.

31. Muenzer J, Wraith JE, BecK M, Giugliani R, Harmatz P, et al. (2006) A phase II/III clinical study of enzyme replacement therpy with idursulfase in mucopolysaccharidosi II (Hunter syndrome). Gnet Med 8(8): 465-473.

32. Harmatz P, Giugliani R, Schwartz I, Guffon N, Teles EL, et al. (2006) Enzyme replacement therapy for mucopolysaccharidosis VI: a phase 3, randomized, double-blind, placebo-controlled, multinational study of recombinant human $\mathrm{N}$-acetylgalavtosamine 4-sulfatase (recombinant human arylsulfatase B or rhASB) and follow-on, opwn-label extension study. j Pediatr 148(4): 533-539.

33. Hendriksz CJ, Burton B, Fleming TR, Harmatz P, Hughes D, et al. (2014) Efficacy and safety of enzyme replacement therapy with BMN 110 (elosulfase alfa) for Morquio A syndrome (mucopolysaccharidosis IVA): a phase 3 randomise placebo-controlled study. J Inherit Metab Dis 37(6): 979-990.

34. Zhu QL, Jiang YX, Liu JB, Liu H, Sun Q et al. (2008) Real-time ultrasound elastography: its potential role in assessment of breast lesions. Ultrasound Med Biol 34(8): 1232-1238.

35. Itoh A, Ueno E, Tohno E, Kamma H, Takahashi H, et al. (2006) Breast disease: clinical application of US elastography for diagnosis. Radiology 239(2): 341-350.

36. Rubaltelli L, Corradin S, Dorigo A, Stabilito M, Tregnaghi A, et al. (2009) Differential diagnosis of benign and malignant thyroid nodules at elastosonography. Ultraschall Med 30(2): 175-179.

37. Pallwein L, Mitterberger M, Struve P, Pinggera G, Horninger W, et al. (2007) Real-time elastography for detecting prostate cancer: preliminary experience. BJU Int 100: 42-46.

\section{Your next submission with Juniper Publishers will reach you the below assets}

- Quality Editorial service

- Swift Peer Review

- Reprints availability

- E-prints Service

- Manuscript Podcast for convenient understanding

- Global attainment for your research

- Manuscript accessibility in different formats

( Pdf, E-pub, Full Text, Audio)

- Unceasing customer service

Track the below URL for one-step submission

https://juniperpublishers.com/online-submission.php 